\title{
Biomolecular Effects of Jb1 (an IGF-I Peptide Analog) in a Rat Model of Oxygen-Induced Retinopathy
}

\author{
ROMY S. BROCK, BISRAT H. GEBREKRISTOS, KATHERINE M. KUNIYOSHI, HOUCHANG D. MODANLOU, \\ MARIO CICERO FALCAO, AND KAY D. BEHARRY
}

Department of Pediatrics [R.S.B., B.H.G., K.M.K., H.D.M., K.D.B.], University of California Irvine, Irvine, California 92868; Department of Pediatrics [B.H.G., K.M.K.], Miller Children's Hospital, Long Beach, California 90806; Department of Pediatrics [M.C.F.], University of Sao Paolo, Sao Paolo, Brazil 03071-000

\begin{abstract}
Low-serum IGF-I levels at birth is a risk factor for the development of retinopathy of prematurity in extremely LBW infants. We tested the hypothesis that JB1 (an IGF-I analog) prevents oxygen-induced retinopathy in our rat model. Neonatal rats were exposed to $50 \%$ oxygen with brief, clustered, hypoxic (12\%) episodes from birth to P14. The pups were treated with s.c. injections of 1) JB1 (1 $\mu \mathrm{g} / \mathrm{d})$ on $\mathrm{P} 1, \mathrm{P} 2$, and $\mathrm{P} 3$ (JB1x3); 2) JB1 (1 $\mu \mathrm{g} / \mathrm{d})$ on alternate days from $\mathrm{P} 1$ to $\mathrm{P} 13$ (JB1x7); or 3) equivalent volume saline. Control littermates were raised in room air (RA) with all conditions identical except for inspired $\mathrm{O}_{2}$. Groups were analyzed after hyperoxia/hypoxia $(\mathrm{H} / \mathrm{H})$ cycling at $\mathrm{P} 14$ or allowed to recover in RA until P21. Systemic and ocular VEGF, soluble VEGFR-1, and IGF-I; retinal vasculature; and gene profile of retinal angiogenesis were assessed. JB1x3 was more effective with associated increases in sVEGFR-1 and decreased retinal pathologies than JB1x7. We conclude that early short-term exposure to systemic JB1 treatment normalizes retinal abnormalities seen with $\mathrm{H} / \mathrm{H}$ cycling, an effect that may involve sVEGFR-1. (Pediatr Res 69: 135-141, 2011)
\end{abstract}

$\mathrm{R}$ etinopathy of prematurity (ROP) is a developmental vascular disorder characterized by abnormal growth of retinal blood vessels in the incompletely vascularized retina of premature newborn infants exposed to high levels of oxygen (1). It is especially severe in extremely LBW (ELBW), premature infants $(<1000 \mathrm{~g})$ who require mechanical ventilation and experience arterial oxygen fluctuations (2). Frequent hyperoxia/hypoxia $(\mathrm{H} / \mathrm{H})$ cycling may lead to neovascularization before recovery in room air (RA). This phenomenon has been demonstrated in our laboratory (3) and is correlated with high levels of ocular VEGF, soluble VEGF receptor (sVEGFR)-1, and IGF-I (3-6).

The role of VEGF and IGF-I in normal and pathologic retinal development is well documented (3-7). The study by Smith et al. (8) demonstrated that JB3 (an IGF-I analog and IGF-I receptor antagonist) administered from P12 until P17 (after oxygen exposure) suppressed oxygen-induced retinopathy (OIR) in mice. These previous reports and our own

Received March 31, 2010; accepted September 23, 2010.

Correspondence: Kay D. Beharry, Division of Neonatology, Department of Pediatrics, University of California, Irvine, 101 The City Drive South, Route 81, Building No. 56, Suite 600, Orange, CA 92868; e-mail: kbeharry@uci.edu

Supported by a grant from Memorial Medical Center Foundation, Long Beach, California.

Presented, in part, at the 2008 Annual Academic Pediatric Society-Society for Pediatric Research Meeting, Honolulu, Hawaii. observations prompted us to hypothesize that JB1 treatment during brief, frequent, clustered $\mathrm{H} / \mathrm{H}$ cycling will prevent OIR in our rat model. We used two treatment strategies a) early, short-term treatment on postnatal days 1, 2, and 3 (P1 to P3) and b) long-term treatment on alternate days from P1 to P13 during the $\mathrm{H} / \mathrm{H}$ cycling period to address specific questions: 1 ) Does systemic administration of an IGF-I receptor antagonist affect ocular levels of IGF-I?; 2) If low systemic IGF-I levels is an indicator of ocular status, will early postnatal administration of JB-I (blocking systemic IGF-I signaling) result in accumulation of ocular VEGF and severe OIR?; 3) If our speculation that the mechanisms involved in the development of severe OIR is activated during $\mathrm{H} / \mathrm{H}$ cycling is true, can treatment with JB-1 prevent neovascularization?; and 4) how does IGF-I suppression influence angiogenesis-related gene expression in the retina?

\section{MATERIALS AND METHODS}

All experiments were approved by the Memorial Medical Center Institutional Animal Care and Use Committee, Long Beach, CA. Animals were managed according to The Association for Research in Vision and Ophthalmology Statement for the Use of Animals in Ophthalmic and Visual Research and the Guide for the Care and Use of Laboratory Animals.

Experimental design. Certified infection-free, timed-pregnant Sprague Dawley rats were purchased from Charles River Laboratories (Wilmington, MA) at $18 \mathrm{~d}$ gestation. The animals were housed in an animal facility with a 12-h-day/12-h-night cycle and provided standard laboratory diet and water ad libitum. Within 1-3 h of birth, newborn rat pups delivering on the same day were pooled from 4 to 5 litters and randomly assigned to expanded litters of 17 pups/litter. The expanded litter size was used to simulate relative postnatal malnutrition in ill ELBW infants. Rat pups raised in large litters have been shown to develop more severe abnormal neovascularization (9). One dam remained with the same litter for the entire study. Each pup was weighed and measured for linear growth (crown to rump) before experimentation. On the day of birth, or postnatal d $0(\mathrm{P} 0)$, the OIR groups were placed in specialized chambers for $\mathrm{H} / \mathrm{H}$ cycling. The $\mathrm{H} / \mathrm{H}$ cycles consisted of $50 \% \mathrm{O}_{2}$ followed by three consecutive brief episodes of hypoxia $\left(12 \% \mathrm{O}_{2}\right)$ for $2 \mathrm{~min}$ each $10 \mathrm{~min}$ apart, every $6 \mathrm{~h}$ for a total of 12 hypoxic cycles per day. This OIR model was modified from a previously validated model $(6,10,11)$ and shown to result in severe OIR in our laboratory (3). Hypoxia of $12 \% \mathrm{O}_{2}$ was used because of the extended time period needed to reach $10 \%$ and the desire to keep the hypoxic episodes brief. Twelve groups were studied. Six groups were exposed to clustered $\mathrm{H} / \mathrm{H}$ cycling for $14 \mathrm{~d}$ from $\mathrm{P} 0$ to $\mathrm{P} 14$ and treated with 1 ) JB1 (an IGF-I peptide analog that potently inhibits the autophosphorylation of the IGF-I receptor by IGF-I) at $1 \mu \mathrm{g} / \mathrm{d}$ on P1, P2, and P3 (JB1x3); 2) JB1 (1 $\mu \mathrm{g} / \mathrm{d})$ on P1, P3, P5, P7, P9, P11, and P13 (JB1x7); or 3) equivalent volume saline.

\footnotetext{
Abbreviations: $\mathbf{C}_{\mathbf{t}}$, cycle threshold; ELBW, extremely LBW; $\mathbf{H} / \mathbf{H}$, hyperoxia/ hypoxia; OIR, oxygen-induced retinopathy; RA, room air; ROP, retinopathy of prematurity; sVEGFR-1, soluble VEGF-1
} 
The dose of JB1 was based on doses of JB3 used by Smith et al. (8). Animals were either killed on P14 (JB1x3, JB1x7, and saline) or allowed to recover in RA until P21. Six groups of normoxic littermates received similar dosing regimens of JB1, and three groups were killed on P14 or P21.

Sample collection. Both eyes from eight rats in each group were enucleated and rinsed in ice-cold PBS $(\mathrm{pH} 7.4)$ on ice. The vitreous fluid was aspirated using a $0.5-\mathrm{mL}$ insulin syringe and placed on ice in sterile Eppendorf tubes. Vitreous fluid was pooled for a total of four samples per group. None of the vitreous fluid samples were contaminated with blood. The retinas were then excised, placed in sterile polypropylene tubes, and snap frozen. To obtain enough tissue, retinas were pooled and a total of four samples were assayed per group. Each sample contained vitreous or retina from four eyes. Of the remaining nine rats, three rats were used for fluorescein-dextran staining, one rat was used for histological analysis of the retinal layers (data not shown), and five rats were used for ADP staining (total of 10 retinal flatmounts per group). Blood samples were collected in sterile Eppendorf tubes after decapitation and pooled for a total of eight samples and placed on ice and allowed to clot for $30 \mathrm{~min}$ before processing. The tubes were centrifuged at $3000 \mathrm{rpm}$ for $20 \mathrm{~min}$ for collection of serum. Vitreous and serum samples were stored in $-20^{\circ} \mathrm{C}$, and retinal samples were stored in $-80^{\circ} \mathrm{C}$ until assay.

Assays. On the day of the assay, retinas were homogenized on ice, centrifuged at $5000 \mathrm{rpm}$ at $4^{\circ} \mathrm{C}$ for $20 \mathrm{~min}$, and then filtered. VEGF, sVEGFR-1, and IGF-I levels were determined in serum, undiluted vitreous fluid and retinal homogenates using commercially available sandwich immunoassay kits for rat/mouse from R \& D Systems, Minneapolis, MN (VEGF and sVEGFR-1) and Diagnostic Systems Laboratories, Webster, TX (IGF-I). IGF-2 (Diagnostic Systems Laboratories) was also determined in serum, according to the manufacturer's protocol, but not in the ocular compartment because of the sample size limitations. Growth factor levels in the retinal homogenates were standardized using total cellular protein levels according to the Bradford method (BioRad Laboratories, Hercules, CA).

Fluorescein-dextran perfusion. To determine retinal vascular development, computer-digitized images of fluorescein-dextran stained retinas from three rats, chosen randomly, in each group were examined. Fluoresceindextran perfusion was performed as previously described (3).

ADPase retinal staining. ADPase staining of the retinas was accomplished according to the method of Penn et al. $(10,11)$. Digital images of the whole flattened, stained retinas were captured at $4 \times$ magnification and saved using the SPOT software (Diagnostic Instruments, Inc., Sterling Heights, MI), Olympus BH-2 microscope (McBain Instruments, Chatsworth, CA), and Dell Optiplex GX280 computer (Dell Computer Corporation, Dallas, TX). Images of the fluorescein-dextran stained retinas were captured at $10 \times$ magnification.

Quantification of retinal neovascularization and retinal scoring. Neovascularization was determined as calculated area $\left(\mu \mathrm{m}^{2}\right)$ of retinal overgrowth extending beyond the avascular zone into the ciliary body in each quadrant of the retinal flatmounts (total 40 measurements/group). The area was outlined on the retinal images using the region selection tool of the image analysis software (SPOT), and the total area was quantified. For retinal scoring, we used a modified version of the scoring system developed by Higgins et al. (12). The scoring criteria included vascular tufts, retinal overgrowth (vessels growing beyond the avascular zone and into the ciliary body), retinal hemorrhage, vessel tortuosity, and persistence of hyaloid vessels. For scoring, each retina was divided into 12 equally sized sections representing the "clock hours." A score of "0" was given if none of the characteristics were found in any of the clock hours; a score of 1 was given if found in $<3$ clock hours; a score of 2 was given if found in 3-5 clock hours; a score of 3 was given if found in 6-8 clock hours; and a score of 4 was given found in 9-12 clock hours. The retinopathy score was calculated by the sum of points for each criteria. A score of $>12$ was considered severe OIR.

Real-time PCR. Total retinal RNA was extracted using RNA Pro solution (MP Bio, Solon, OH) using the FastPrep-24 instrument (MP Bio) according to the manufacturer's protocol. The amount of RNA was quantified at $260 \mathrm{~nm}$ using a Beckman spectrophotometer and diluted to $1 \mu \mathrm{g} / \mu \mathrm{L}$. Cleanup of the RNA was performed using RNEasy mini cleanup kits (Qiagen, Valencia, CA) followed by on-column treatment with DNase I (Qiagen). Reverse transcriptase was performed using a $\mathrm{RT}^{2}$ First Strand kit purchased from SABiosciences, Frederick, MD. The real-time PCR arrays were done in duplicate using the rat Angiogenic Growth Factors \& Angiogenesis Inhibitors PCR Array System (SABiosciences) using a BioRad IQ5 real-time instrument (BioRad Laboratories). Each PCR array plate consisted of a panel of five housekeeping genes to normalize the PCR array data; replicate genomic DNA controls to detect nontranscribed genomic DNA contamination with a high levels of sensitivity; replicate reverse transcription controls to test the efficiency of the $\mathrm{RT}^{2}$ first strand reaction; and replicate positive PCR controls to test the efficiency of the PCR reaction itself using a predispensed artificial DNA sequence and the primer set that detects it. The replicate controls also tests for interwell and intraplate consistency. Calculations were made by exporting the data into an Excel spreadsheet using the SABiosciences PCR Array Data Analysis Excel Template and uploading the real-time amplification data into the SABiosciences $\mathrm{RT}^{2}$ Profiler PCR Array Data Analysis web portal. Quantitative PCR was based on the cycle threshold $\left(\mathrm{C}_{\mathrm{t}}\right)$ value. A gene was considered not detectable if the $C_{t}$ value was $\geq 35$. The [Delta] $C_{t}$ for each gene was calculated as $C_{t}$ (gene of interest) $-C_{t}$ (housekeeping gene).

Statistical analysis. One-way ANOVA was used to determine differences among the groups for normally distributed data, and Kruskal-Wallis test was used for nonnormally distributed data following Bartlett's test for equality of variances. Post hoc analysis was performed using the Tukey, Bonferoni, and Student-Newman-Keuls tests for significance. To compare data between RA and $\mathrm{H} / \mathrm{H}$ groups, unpaired $t$ test was used for normally distributed data, and Mann-Whitney $U$ tests were used for nonnormal data following Levene's test for equality of variances. Significance was set at $p<0.05$, and data are reported as mean \pm SEM. All analyses were two tailed and performed using SPSS version 16.0 (SPSS, Inc. Chicago, IL)

\section{RESULTS}

Somatic growth. As shown in Table $1, \mathrm{H} / \mathrm{H}$ cycling decreased body weight and linear growth at P14. JB1x3 treatment in RA and $\mathrm{H} / \mathrm{H}$ cycling resulted in higher body weights and increased linear growth in $\mathrm{H} / \mathrm{H}$ cycling than their salinetreated littermates at P14. JB1x7 treatment in $\mathrm{H} / \mathrm{H}$ cycling decreased body weight and linear growth compared with saline and JB1x3 in H/H cycling. By P21, body weight and linear growth remained suppressed with JB1 treatment in $\mathrm{H} / \mathrm{H}$ cycling.

VEGF protein. At $\mathrm{P} 14, \mathrm{JB} 1 \times 3$ treatment in $\mathrm{RA}$ suppressed VEGF in the serum compared with saline. At P21, JB1x7 in $\mathrm{H} / \mathrm{H}$ cycling increased serum VEGF levels but not significantly (Table 2). In the retina at P14, only JB1x7 decreased VEGF levels in RA compared with saline RA. In H/H cycling,

Table 1. Effect on somatic growth

\begin{tabular}{|c|c|c|c|c|c|c|}
\hline & \multicolumn{2}{|c|}{ Sal } & \multicolumn{2}{|c|}{$\mathrm{JB} 1 \mathrm{x} 3$} & \multicolumn{2}{|c|}{$\mathrm{JB} 1 \mathrm{x} 7$} \\
\hline \multicolumn{7}{|c|}{ Body weight (g) } \\
\hline $\mathrm{P} 21$ & $36.4 \pm 1.2$ & $37.8 \pm 1.2$ & $39.2 \pm 1.0$ & $34.7 \pm 1.1 \dagger$ & $34.1 \pm 0.56$ & $32.5 \pm 1.00 \ddagger$ \\
\hline \multicolumn{7}{|c|}{ Linear growth $(\mathrm{cm})$} \\
\hline P14 & $6.3 \pm 0.10$ & $5.7 \pm 0.14 \dagger$ & $6.5 \pm 0.11$ & $6.0 \pm 0.12 \dagger t$ & $5.7 \pm 0.09 *$ & $5.3 \pm 0.10 \dagger$ \\
\hline
\end{tabular}


Table 2. Effect on systemic growth factors

\begin{tabular}{|c|c|c|c|c|c|c|}
\hline & \multicolumn{2}{|c|}{ Sal } & \multicolumn{2}{|c|}{$\mathrm{JB} 1 \times 3$} & \multicolumn{2}{|c|}{ JB $1 \times 7$} \\
\hline & RA & $\mathrm{H} / \mathrm{H}$ cycling & RA & $\mathrm{H} / \mathrm{H}$ cycling & RA & $\mathrm{H} / \mathrm{H}$ cycling \\
\hline \multicolumn{7}{|c|}{ VEGF (pg/mL) } \\
\hline P14 & $28.3 \pm 3.6$ & $17.9 \pm 4.3$ & $12.3 \pm 3.8 *$ & $16.5 \pm 2.8$ & $21.6 \pm 2.5$ & $27.5 \pm 3.0$ \\
\hline $\mathrm{P} 21$ & $6.5 \pm 3.3$ & $9.4 \pm 3.0$ & $9.7 \pm 3.3$ & $4.4 \pm 2.9$ & $8.8 \pm 1.9$ & $16.6 \pm 3.0$ \\
\hline \multicolumn{7}{|c|}{ sVEGFR-1 (pg/mL) } \\
\hline P14 & $1224.1 \pm 363.6$ & $1461.4 \pm 166.1$ & $4304.5 \pm 366.8^{*}$ & $3562.5 \pm 439.7 \dagger$ & $4428.3 \pm 434.2 \ddagger$ & $5834.40 \pm 903.5 \dagger \S$ \\
\hline $\mathrm{P} 21$ & $1923.7 \pm 108.0$ & $1877.5 \pm 328.8$ & $6499.6 \pm 1365.0 *$ & $6011.8 \pm 800.2 \dagger$ & $387.7 \pm 57.3$ & $401.7 \pm 31.7$ \\
\hline \multicolumn{7}{|c|}{ IGF-I (ng/mL) } \\
\hline P14 & $68.8 \pm 11.2$ & $39.7 \pm 6.09$ & $75.6 \pm 6.6$ & $38.2 \pm 2.8 \S$ & $130.2 \pm 28.9$ & $49.3 \pm 3.1 \S$ \\
\hline $\mathrm{P} 21$ & $144.2 \pm 32.9$ & $246.4 \pm 27.3$ & $182.7 \pm 12.3$ & $145.7 \pm 24.0 \dagger$ & $120.5 \pm 8.1$ & $138.6 \pm 26.4 \dagger$ \\
\hline \multicolumn{7}{|c|}{ IGF-II (ng/mL) } \\
\hline P14 & $129.8 \pm 1.2$ & $147.5 \pm 10.4$ & $160.2 \pm 13.5$ & $144.3 \pm 8.2$ & $154.4 \pm 16.9$ & $104.1 \pm 3.8 \dagger$ \\
\hline $\mathrm{P} 21$ & $131.2 \pm 4.5$ & $131.6 \pm 1.2$ & $132.0 \pm 1.4$ & $131.9 \pm 0.9$ & $128.7 \pm 1.9$ & $166.0 \pm 3.2 \dagger$ \\
\hline
\end{tabular}

$n=8$ samples/group. Saline (Sal)-treated (control) animals received equivalent volume saline.

$* p<0.01$.

$\dagger p<0.05$ vs Sal H/H cycling.

‡ $p<0.001$ vs Sal RA.

$\S p<0.05$ vs RA.

II $p<0.05$ vs RA.

JB1x3, animals that received i.p. injections of JB1 (1 $\mu \mathrm{g} /$ day) on P0, P1, and P2; JB1x7, animals that received JB1 ( $\mu$ g/day) on P1, P3, P5, P7, P9, P11, and P13.

saline treatment resulted in lower VEGF levels compared with saline treatment in RA. JB1x3 treatment increased VEGF compared with saline (Fig. 1A). At P21, VEGF was increased in the saline-treated group in $\mathrm{H} / \mathrm{H}$ cycling compared with RA. In the vitreous fluid, VEGF levels were generally lower with $\mathrm{H} / \mathrm{H}$ cycling compared with $\mathrm{RA}$, but significance was achieved only in the saline-treated group compared with saline in RA. JB1x3 treatment in RA decreased vitreous fluid VEGF levels compared with saline RA (Fig. 2A).

sVEGFR-1 protein. SVEGFR-1 protein levels were increased in the serum at P14 in RA and $\mathrm{H} / \mathrm{H}$ cycling with $\mathrm{JB} 1 \times 3$ and JB1x7. At P21, the increases in the serum sVEGFR-1 levels were sustained in the JB- $1 \times 3$ group, but an opposite effect was seen with JB1X7 (Table 2). In the retina at P14, the levels of sVEGFR-1 were decreased with $\mathrm{H} / \mathrm{H}$ cycling in the saline-treated group compared with saline treat- ment in RA. In contrast, JB1x3 treatment in RA and $\mathrm{H} / \mathrm{H}$ cycling increased retinal sVEGFR-1 levels compared with saline treatment. JB1x7 in RA and $\mathrm{H} / \mathrm{H}$ cycling suppressed retinal sVEGFR-1 (Fig. 1B). Similar effects occurred at P21. In the vitreous fluid, only JB1x7 in $\mathrm{H} / \mathrm{H}$ cycling suppressed sVEGFR-1 levels at P14 and P21 (Fig. 2B and E).

IGF-I protein. At $\mathrm{P} 14$, serum levels of IGF-1 were lower in all $\mathrm{H} / \mathrm{H}$ cycling groups compared with $\mathrm{RA}$. There were no differences in serum IGF-I among the RA groups. At P21, both JB1x3 and JB1x7 treatment in $\mathrm{H} / \mathrm{H}$ cycling decreased serum IGF-1 levels compared with saline in $\mathrm{H} / \mathrm{H}$ cycling (Table 2). In the retina at $\mathrm{P} 14, \mathrm{JB} 1 \times 3$ treatment in $\mathrm{RA}$ decreased IGF-I levels compared with saline and JB1x7. In H/H cycling, retinal IGF-I levels were lower with saline treatment compared with RA and higher with JB1x7 compared with saline and JB1x3 treatment in $\mathrm{H} / \mathrm{H}$ cycling (Fig.
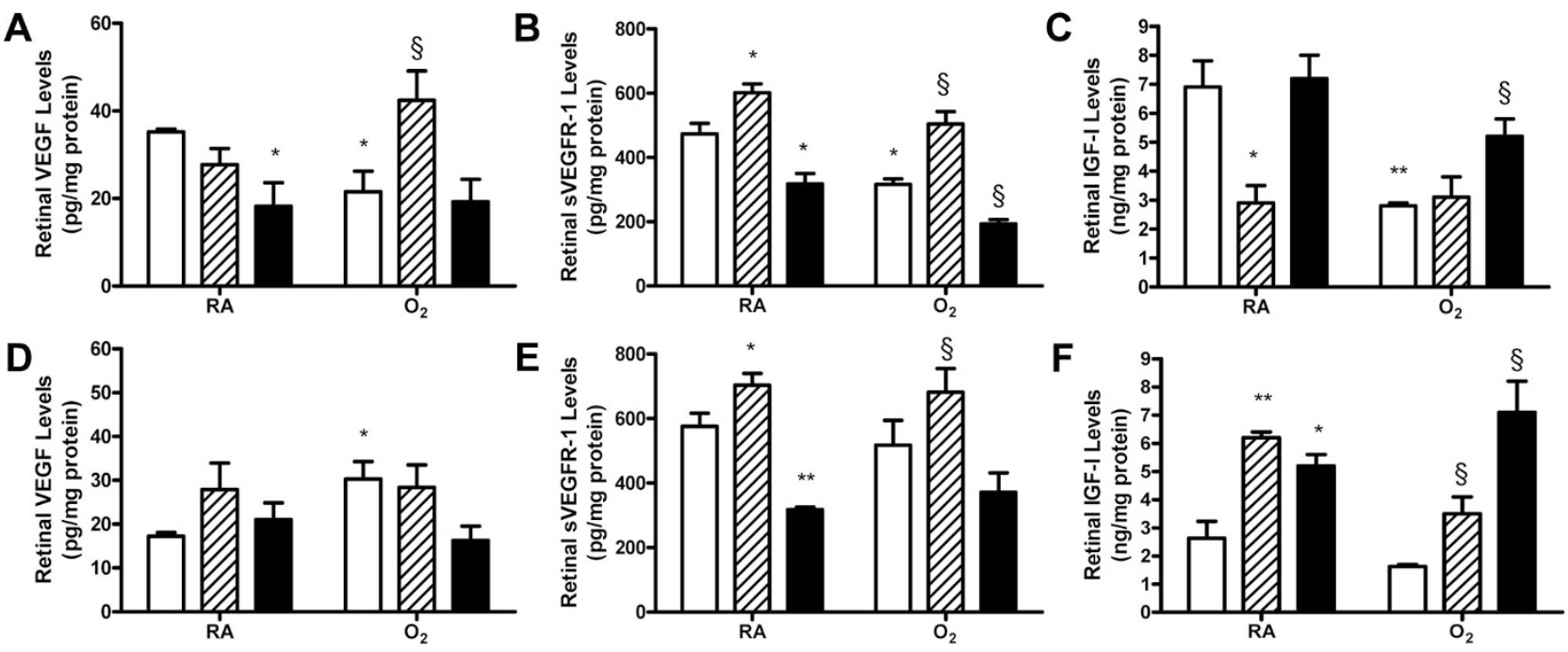

Figure 1. Effects of frequent, brief, clustered H/H cycling on retinal VEGF, sVEGFR-1, and IGF-I protein at P14 $(A-C)$ and P21 $(D-F)$. The open bar represents the saline-treated group, the lined bar represents the JB1x3-treated group, and the solid black bar represents the JB1x7 group. Data are expressed as mean \pm SEM ( $n=4$ samples/group; $* p<0.05,{ }^{* *} p<0.01 v s$ saline RA, and $\$ p<0.05 v s$ saline H/H cycling). 
1C). At $\mathrm{P} 21$, an opposite rebound effect was noted with both treatment groups in RA and $\mathrm{H} / \mathrm{H}$ cycling (Fig. $1 F$ ). In the vitreous fluid, IGF-I levels were increased with JB1x7 treatment in RA and $\mathrm{H} / \mathrm{H}$ cycling at P14 (Fig. 2C). A similar effect occurred at P21 (Fig. 2F).

IGF -2 protein. At $\mathrm{P} 14$, treatment with $\mathrm{JB}-1 \times \mathrm{x}$ in $\mathrm{H} / \mathrm{H}$ cycling decreased serum IGF-2 levels compared with saline and JB1x3 treatment. A rebound effect was noted at $\mathrm{P} 21$ with $\mathrm{JB} 1 \times 7$ in $\mathrm{H} / \mathrm{H}$ cycling compared with saline and JB1x3. No significant differences were determined in the ocular compartment between the three treatment groups in RA or $\mathrm{H} / \mathrm{H}$ cycling (Table 2).

Retinal neovascularization. At P14, the extent of vascularization was decreased in the JB1x 3 treated $\left(1.4 \times 10^{5}\right)$ groups in $\mathrm{H} / \mathrm{H}$ cycling compared with saline treatment in $\mathrm{RA}(1.7 \times$ $\left.10^{5}, p<0.05\right)$ and $\mathrm{H} / \mathrm{H}$ cycling $\left(2.0 \times 10^{5}, p<0.01\right)$ and JB1x7 treatment in RA $\left(1.5 \times 10^{5}, p<0.05\right)$ and $\mathrm{H} / \mathrm{H}$ cycling $\left(1.7 \times 10^{5}, p<0.05\right)$. At $\mathrm{P} 21$, the area of retinal overgrowth was extended to $2.5 \times 10^{5}(p<0.01)$ in the saline-treated $\mathrm{H} / \mathrm{H}$ cycling group compared with $1.8 \times 10^{5}$ in the saline-treated RA littermates. Similar extents of retinal vascular overgrowth was quantified in the JB1x7 H/H cycling group $\left(2.6 \times 10^{5}, p<0.01\right)$ but not in JB1x3. Retinal scoring for vascular pathology revealed that $90 \%$ of the retinal flatmounts in the 14-d saline-treated $\mathrm{H} / \mathrm{H}$ groups scored $>12$. This was associated with persistence of hyaloid vessels in all clock hours, tortuosity, hemorrhage, and vascular overgrowth (Fig. 3A, arrows). Few vascular tufts were present. JB1x 3 and JB1 7 treatment scored $<12$ in all flatmounts at $\mathrm{P} 14$. At $\mathrm{P} 21,70 \%$ of the saline-treated $\mathrm{H} / \mathrm{H}$ groups scored $>12$. This was associated with extensive punctuate hemorrhages in all clock hours, some tortuous vessels and vascular overgrowth (Fig. 4A, arrows). Similarly, 50\% of retinas in the JB1x7 RA groups scored $>12$ because of vascular overgrowth, tortuosity, and persistence of hyaloid vessels (Fig. 4C, arrows). A greater percentage $(90 \%)$ of retinas in the JB1x7 $\mathrm{H} / \mathrm{H}$ cycling group scored $>12$ due to a predominance of tortuous vessels, vascular overgrowth, and punctuate hemorrhage (Fig. $4 F$, arrows).
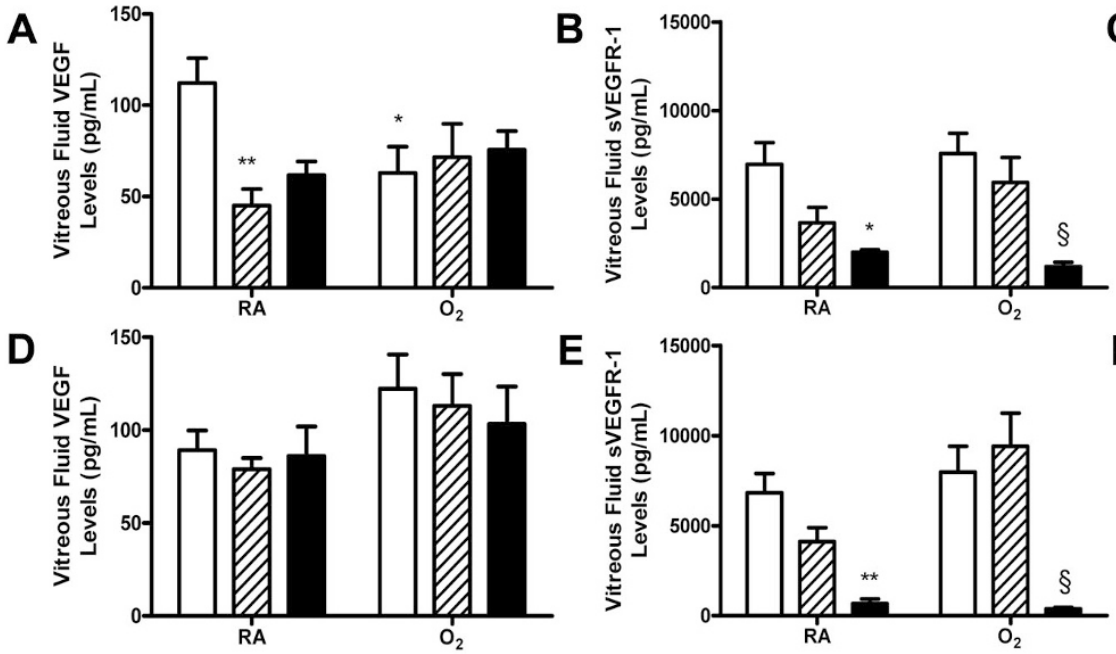

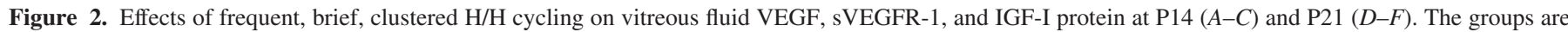

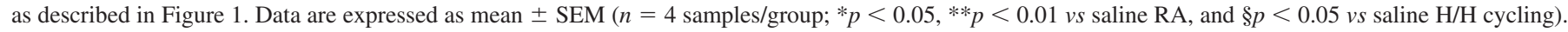
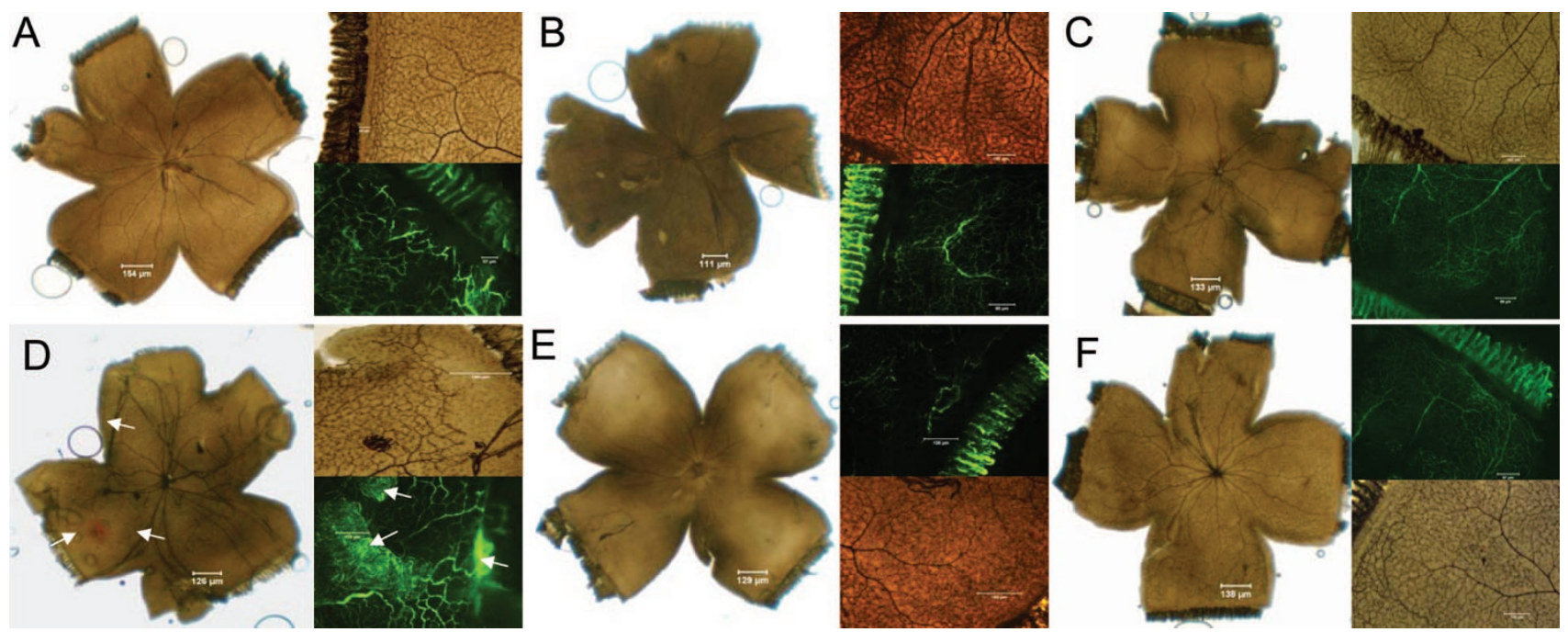

$\mathbf{F}$

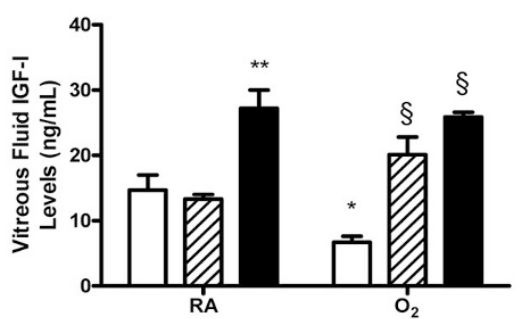

Figure 3. Representative retinal flatmounts showing ADPase (whole retinas) and fluorescein-dextran- (inset) stained retinas from 14-d-old rat pups treated with saline (control), JB1x3, or JB1x7 in RA $(A-C)$ and $\mathrm{H} / \mathrm{H} 50 \% / 12 \% \mathrm{O}_{2}$ cycling $(D-F)$ for $14 \mathrm{~d}$. Five rats were used for ADPase staining and three rats for fluorescein-dextran staining. Images of the whole retinal flatmounts were taken at $\times 4$ magnification. Inset images were taken at $\times 10$ magnification. 

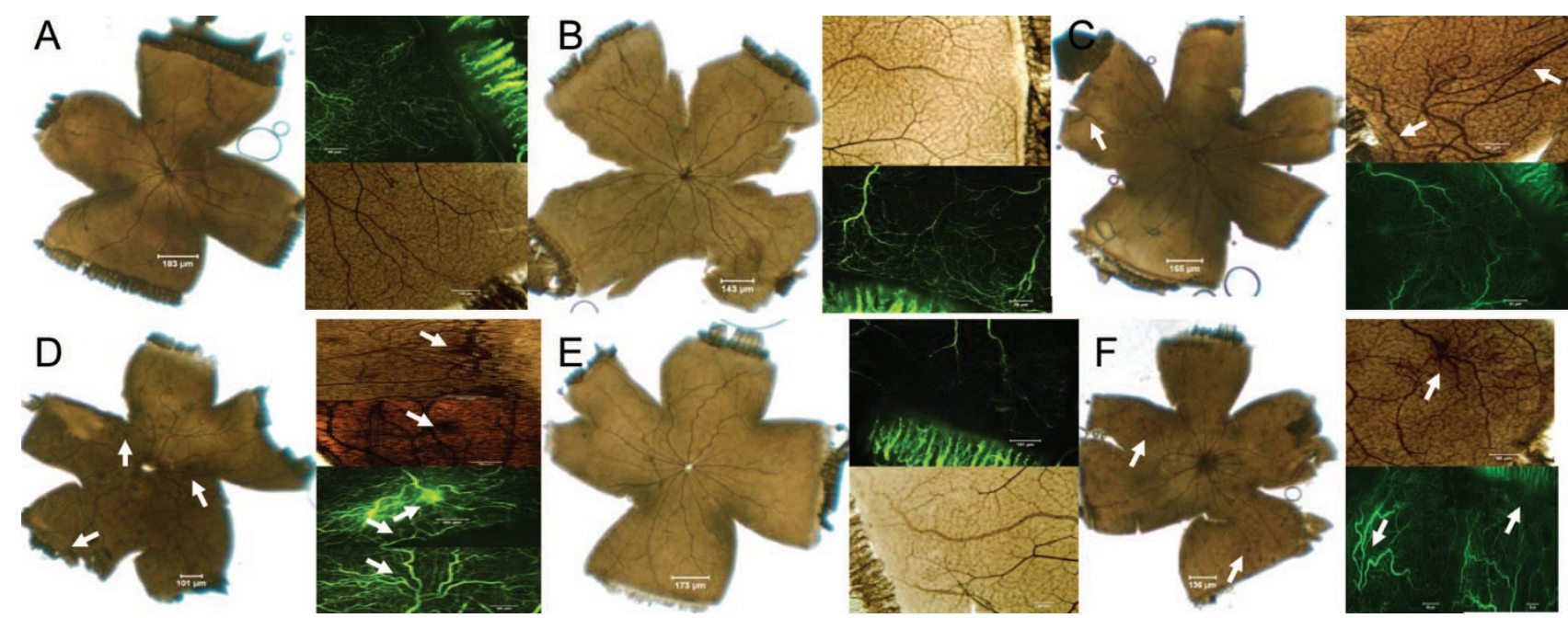

Figure 4. Representative retinal flatmounts showing ADPase (whole retinas) and fluorescein-dextran- (inset) stained retinas from 21-d-old rat pups treated with saline (control), JB1x3, or JB1x7 in RA $(A-C)$ and $\mathrm{H} / \mathrm{H} 50 \% / 12 \% \mathrm{O}_{2}$ cycling $(D-F)$ for $14 \mathrm{~d}$ followed by $7 \mathrm{~d}$ of recovery in RA. Five rats were used for ADPase staining and three rats for fluorescein-dextran staining. Images of the whole retinal flatmounts were taken at $\times 4$ magnification. Inset images were taken at $\times 10$ magnification.

Table 3. Gene expression of angiogenic growth factors in the retina of neonatal rats at 14 and 21 d postnatal age

\begin{tabular}{|c|c|c|c|c|c|}
\hline Gene & $\begin{array}{c}14-\mathrm{DO}_{2} \\
\mathrm{Sal}\end{array}$ & $\begin{array}{c}\text { 14-DRA } \\
\text { JB1x3 }\end{array}$ & $\begin{array}{c}14-\mathrm{DO}_{2} \\
\mathrm{JB} 1 \mathrm{x} 3\end{array}$ & $\begin{array}{c}\text { 14-DRA } \\
\text { JB1x7 }\end{array}$ & $\begin{array}{c}14-\mathrm{DO}_{2} \\
\mathrm{JB} 1 \times 7\end{array}$ \\
\hline CSF3 & -11.8 & -29.1 & -9.5 & -10 & -20.4 \\
\hline$F G F 1$ & -1.6 & -1.4 & -1.4 & -1.3 & 1.0 \\
\hline$F G F 2$ & -9.1 & -4 & -3.3 & -3.4 & -2.5 \\
\hline$L E P$ & -4.3 & -2.5 & -2.6 & -1.6 & -1.9 \\
\hline$P D G F B$ & 1.0 & -1.1 & -2.0 & -1.7 & 1.1 \\
\hline$P G F$ & -1.2 & 1.0 & -2.6 & 1.1 & 1.2 \\
\hline$T G F A$ & -1.6 & 1.0 & -1.3 & 1.4 & -1.2 \\
\hline$V E G F A$ & -1.0 & 1.0 & 1.6 & -1.1 & -1.5 \\
\hline Gene & $\begin{array}{c}21-\mathrm{DO}_{2} \\
\mathrm{Sal}\end{array}$ & $\begin{array}{c}\text { 21-DRA } \\
\text { JB1x3 }\end{array}$ & $\begin{array}{c}21-\mathrm{DO}_{2} \\
\mathrm{JB} 1 \mathrm{x} 3\end{array}$ & $\begin{array}{c}\text { 21-DRA } \\
\text { JB } 1 \times 7\end{array}$ & $\begin{array}{c}21-\mathrm{DO}_{2} \\
\mathrm{JB} 1 \times 7\end{array}$ \\
\hline$C S F 3$ & 5.1 & -7.5 & -3.0 & 4.8 & 3.9 \\
\hline$F G F 1$ & 2.0 & -1.3 & -1.2 & 11.3 & 1.2 \\
\hline$F G F 2$ & 7.0 & -2.5 & -4.4 & 1.6 & 1.7 \\
\hline$L E P$ & 17.7 & -11.5 & -21.3 & 1.6 & 4.1 \\
\hline$P D G F B$ & 1.8 & -1.2 & -1.9 & -8.7 & -1.0 \\
\hline$P G F$ & 1.1 & 1.3 & -1.9 & 10.7 & 1.7 \\
\hline$T G F A$ & 2.2 & -2.4 & -2.1 & 3.6 & 1.3 \\
\hline$V E G F A$ & 5.0 & -1.0 & -1.4 & 6.7 & 1.1 \\
\hline
\end{tabular}

Data are fold change from saline-treated 14- or 21-d RA littermates. All data were corrected using five different housekeeping genes. Genes are selected from a profile of 84 genes. In alphabetical order, the genes of interest are as follows: $C S F 3$, colony stimulating factor $3 ; F G F 1-2$, fibroblast growth factor 1 or 2; $L E P$, leptin; $P D G F B$, platelet-derived growth factor beta; $F G F A$, transforming growth factor alpha; and $V E G F A$, vascular endothelial growth factor $\mathrm{A}$.

Angiogenesis-related gene mRNA expression. Tables 3-5 show the fold difference from saline treatment in RA in angiogenesis-related genes in the retinas at P14 and P21. At P14, mRNA expression of all genes was down-regulated except $P D G F B$ with saline treatment in $\mathrm{H} / \mathrm{H}$ cycling. JB1x3 treatment in $\mathrm{RA}$ and $\mathrm{H} / \mathrm{H}$ cycling preserved retinal VEGFA expression whereas treatment with JB1x7 did not. At P21, an opposite effect was seen with saline treatment. JB1x3 treatment in $\mathrm{RA}$ and $\mathrm{H} / \mathrm{H}$ cycling decreased VEGFA mRNA expression but JB1x7 did not (Table 3). Expression of positive
Table 4. Gene expression of positive regulators of angiogenesis in the retina of neonatal rats at 14 or $21 d$ postnatal age

\begin{tabular}{|c|c|c|c|c|c|}
\hline Gene & $\begin{array}{c}14-\mathrm{DO}_{2} \\
\mathrm{Sal}\end{array}$ & $\begin{array}{c}\text { 14-DRA } \\
\text { JB1x3 }\end{array}$ & $\begin{array}{c}14-\mathrm{DO}_{2} \\
\mathrm{JB} 1 \mathrm{x} 3\end{array}$ & $\begin{array}{c}\text { 14-DRA } \\
\text { JB1x7 }\end{array}$ & $\begin{array}{c}14-\mathrm{DO}_{2} \\
\mathrm{JB} 1 \times 7\end{array}$ \\
\hline$K D R$ & -1.0 & 1.2 & 2.0 & -1.2 & -1.2 \\
\hline NTRK2 & -1.6 & -1.5 & -1.1 & -1.8 & -1.3 \\
\hline$P T P R J$ & -1.1 & -1.2 & -1.1 & 1.0 & 1.1 \\
\hline RASAl & 1.2 & 1.4 & 1.3 & 1.0 & -1.1 \\
\hline$R H O B$ & -1.1 & -1.2 & -1.7 & -1.0 & -1.3 \\
\hline RUNX1 & -6.2 & -11.8 & -68.1 & -8.0 & -44.5 \\
\hline $\mathrm{SHH}$ & -1.6 & -2.6 & -3.3 & -2.8 & -1.1 \\
\hline Gene & $\begin{array}{c}21-\mathrm{DO}_{2} \\
\mathrm{Sal}\end{array}$ & $\begin{array}{c}\text { 21-DRA } \\
\text { JB1x3 }\end{array}$ & $\begin{array}{c}21-\mathrm{DO}_{2} \\
\mathrm{JB} 1 \mathrm{x} 3\end{array}$ & $\begin{array}{c}\text { 21-DRA } \\
\text { JB1x7 }\end{array}$ & $\begin{array}{c}21-\mathrm{DO}_{2} \\
\mathrm{JB} 1 \times 7\end{array}$ \\
\hline$K D R$ & 1.7 & 1.4 & 2.0 & 23.5 & 1.6 \\
\hline NTRK2 & -1.3 & 1.1 & 1.2 & 10.2 & 1.5 \\
\hline$P T P R J$ & -1.2 & 1.0 & 1.5 & 7.3 & 1.2 \\
\hline RASAl & -1.1 & 1.6 & 1.1 & 16.7 & 1.2 \\
\hline RHOB & -1.2 & 1.2 & 1.4 & 7.9 & 1.1 \\
\hline RUNX1 & -1.5 & 1.8 & 1.1 & 5.7 & 2.3 \\
\hline $\mathrm{SHH}$ & -1.0 & 1.5 & 1.2 & 8.3 & 1.0 \\
\hline
\end{tabular}

Data are fold change from saline-treated 14- or 21-d RA littermates. All data were corrected using five different housekeeping genes. Genes are selected from a profile of 84 genes. In alphabetical order, the genes of interest are as follows: $K D R$, kinase insert domain protein receptor (VEGFR-2); NTRK2, neurotrophic tyrosine kinase receptor type 2; PTPRJ, protein tyrosine phosphatase receptor type J; RASA1, RASp21 protein activator (GTPase activating protein) 1 ; RHOB, RAS homolog gene family B; RUNX1, runtrelated transcription factor 1 ; and $S H H$, sonic hedgehog.

regulators of angiogenesis was down-regulated in the 14-d and 21-d retinas exposed to $\mathrm{H} / \mathrm{H}$ cycling and saline treatment. A robust down-regulation in RUNX1 gene expression was noted in all groups at P14. This effect was abolished at P21 except in the saline-treated group. Treatment with JB1 in RA and $\mathrm{H} / \mathrm{H}$ cycling up-regulated all angiogenesis-related genes at P21 (Table 4). Interestingly, RUNX1, a gene involved in matrix remodeling and proliferation was robustly downregulated with $\mathrm{H} / \mathrm{H}$ cycling and JB1 treatment at $\mathrm{P} 14$ and remained suppressed at $\mathrm{P} 21$ in the saline-treated $\mathrm{H} / \mathrm{H}$ group but not in the JB1-treated groups. A similar effect was noted 
Table 5. Gene expression of negative regulators of angiogenesis in the retina of neonatal rats at 14 and 21 d postnatal age

\begin{tabular}{|c|c|c|c|c|c|}
\hline Gene & $\begin{array}{c}14-\mathrm{DO}_{2} \\
\mathrm{Sal}\end{array}$ & $\begin{array}{c}\text { 14-DRA } \\
\text { JB1x3 }\end{array}$ & $\begin{array}{c}14-\mathrm{DO}_{2} \\
\mathrm{JB} 1 \times 3\end{array}$ & $\begin{array}{c}\text { 14-DRA } \\
\text { JB1x7 }\end{array}$ & $\begin{array}{c}14-\mathrm{DO}_{2} \\
\mathrm{JB} 1 \times 7\end{array}$ \\
\hline$B A I$ & -2.2 & -1.3 & -2.3 & -1.1 & -1.1 \\
\hline COL18A1 & -1.2 & 1.0 & -1.0 & 1.1 & 1.6 \\
\hline COLAA3 & 2.3 & 5.0 & 2.6 & 2.2 & 4.4 \\
\hline CRHR2 & -1.3 & -1.8 & -1.1 & -1.8 & -1.2 \\
\hline FN1 & -2.3 & -4.8 & -6.8 & -3.2 & -3.5 \\
\hline$P L G$ & -10.0 & -2.4 & -6.1 & -2.8 & -4.5 \\
\hline$P R L$ & -18.5 & -10.9 & -6.1 & -2.7 & -3.7 \\
\hline PRL7D1 & -8.4 & -3.9 & -5.2 & -3.2 & -3.8 \\
\hline RNH1 & 1.0 & 1.6 & 1.1 & -1.3 & -1.1 \\
\hline THBS1 & -1.5 & -1.7 & -4.7 & -1.5 & -2.4 \\
\hline TIE1 & -1.0 & -1.7 & -2.4 & 1.1 & -1.9 \\
\hline TIMP1 & 1.1 & 1.3 & 1.2 & -1.1 & 1.3 \\
\hline TIMP2 & -1.6 & -2.0 & -1.8 & -1.8 & -2.0 \\
\hline TIMP3 & 1.2 & 1.1 & -1.1 & 1.1 & 1.9 \\
\hline TIMP4 & -1.2 & -1.8 & 1.1 & -2.3 & -1.4 \\
\hline Gene & $\begin{array}{c}21-\mathrm{DO}_{2} \\
\mathrm{Sal}\end{array}$ & $\begin{array}{c}\text { 21-DRA } \\
\text { JB1x3 }\end{array}$ & $\begin{array}{c}21-\mathrm{DO}_{2} \\
\mathrm{JB} 1 \times 3\end{array}$ & $\begin{array}{c}\text { 21-DRA } \\
\text { JB1x7 }\end{array}$ & $\begin{array}{c}21-\mathrm{DO}_{2} \\
\mathrm{JB} 1 \times 7\end{array}$ \\
\hline$B A I$ & -1.2 & 1.7 & 1.1 & 13.5 & 1.5 \\
\hline COL18A1 & -1.1 & 1.3 & -1.2 & -52.1 & 1.4 \\
\hline COLAA3 & 1.7 & 2.4 & 1.3 & 17.6 & 2.3 \\
\hline CRHR2 & -1.9 & 1.1 & -1.5 & 3.1 & -1.1 \\
\hline FN1 & 1.2 & 1.6 & 1.9 & 11.4 & 1.1 \\
\hline$P L G$ & -10.2 & -11.5 & -14.9 & 1.6 & -1.4 \\
\hline$P R L$ & -33.9 & -22.1 & -41.0 & -1.1 & -1.8 \\
\hline PRL7D1 & -14.3 & -11.5 & -21.3 & 1.6 & 1.2 \\
\hline RNHI & 2.0 & 2.4 & 1.8 & 1.1 & 2.3 \\
\hline THBS1 & 1.1 & -1.2 & -1.1 & -16.0 & -1.5 \\
\hline TIE1 & -1.5 & -1.2 & -1.7 & 6.7 & -1.3 \\
\hline TIMP1 & 1.1 & 1.2 & 1.1 & 14.3 & 1.4 \\
\hline TIMP2 & 1.1 & -52.4 & 1.0 & 8.5 & 1.0 \\
\hline TIMP3 & -1.0 & 1.0 & -1.4 & 6.9 & -1.1 \\
\hline TIMP4 & 1.1 & 1.4 & -1.1 & 10.7 & -1.0 \\
\hline
\end{tabular}

Data are fold change from saline-treated 14- or 21-d RA littermates. All data were corrected using five different housekeeping genes. Genes are selected from a profile of 84 genes. In alphabetical order, the genes of interest are as follows: BAI, brain-specific angiogenesis inhibitor 1; COL18A1, collagen, type XVIII, alpha 1; COLAA3, collagen type IV, alpha 3; CRHR2, corticotrophin releasing hormone receptor $2 ; F N 1$, fibronectin 1; $P L G$, plasminogen; $P R L$, prolactin; $P R L 7 D 1$, prolactin family 7 , subfamily $\mathrm{D}$, member 1; $R N H 1$, ribonuclease/angiogenin inhibitor 1; THBS, thrombospondin 1; TIE1, tyrosine kinase with immunoglobulin-like and EGF-like domains 1; and TIMP1-4, tissue inhibitor of metalloproteinase 1-4.

with $S H H$, a retinal angiogenesis gene. The effects on negative regulators of angiogenesis were variable, but the genes in the prolactin family were most affected by $\mathrm{H} / \mathrm{H}$ cycling and JB1 treatment. Of the TIMP family, TIMP-2 was mostly influenced by JB1x3 at P21 (Table 5).

\section{DISCUSSION}

Systemic treatment with three early postnatal doses of JB1 during $\mathrm{H} / \mathrm{H}$ cycling resulted in successful suppression of OIR with no adverse effects on anthropometric growth. In contrast, intermittent exposure with seven alternate doses throughout the $\mathrm{H} / \mathrm{H}$ cycling period resulted in decreased body growth at P21 associated with higher ocular VEGF and IGF-1 levels as well as vascular tortuosity albeit, decreased retinal neovascularization compared with saline-treated retinas. IGF-I is a major growth regulator and positively correlates with body weight and body length (13). Therefore, short-term use of JB1 most likely resulted in an initial suppression followed by a subsequent rebound in IGF-1 thereby triggering catch-up growth. This may explain why the short-term treated pups were bigger. JB1 competes with IGF-1 by binding the IGF-1 receptor. It acts as a selective and potent IGF-1R antagonist preventing its autophosphorylation, with no activity in IGF-II $(14,15)$. Smith et al. $(8)$ administered a similar IGF-I analog, JB3, after exposure to oxygen, with similar suppressive effects on ischemia-induced retinopathy. In this study, the drug was administered during exposure to oxygen because previous studies in our laboratory showed that the mechanisms involved in severe OIR are triggered before recovery in RA (3).

Interestingly, our data showed that the serum levels of IGF-1 were suppressed during $\mathrm{H} / \mathrm{H}$ cycling with both JB1 treatment regimens. An opposite effect was seen in the ocular compartment with IGF-1 levels increasing as a function of JB1 exposure time. These findings provide support of our previous study which showed that the levels of IGF-I in the systemic and ocular compartments differ possibly because of the ocular-blood barrier (16). The increase in ocular IGF-1 levels in response to JB1 treatment may be due to increased production of IGF-1 through hypoxia-induced IGF-1 transcriptional activation (17). Alternatively, the effect may be explained by accumulation of IGF-I due to binding of IGF-1R to JB1, thereby preventing IGF-I transport and uptake. In addition, the status of the IGF-1R is extremely dependent on local and circulating levels of IGF-1 (18). Thus, an increase in the IGF-1 concentrations may cause a decrease in IGF-1R numbers. The study by Hellstrom et al. (19) suggested that low systemic IGF-1 in mice prevents normal retinal vascular development despite the presence of VEGF, which might lead to increased neovascularization. We found that the use of an IGF-1 inhibitor during the first $3 \mathrm{~d}$ of life indeed suppressed normal retinal development up to $14 \mathrm{~d}$ of life. However, longer exposure with JB1x7 had an opposite effect on IGF-1 in the ocular compartment and was not associated with exacerbated neovascularization at P21, as expected. These intriguing findings raise the possibility that a rebound increase in IGF-I levels after exposure to JB1 may have provided protection against oxidative injury and contributed to hypoxia tolerance as previously reported by Wang et al. (17). In that context, the JB1x3 dosing regimen was more effective for normalization of retinal IGF-I levels and retinal vascular abnormalities seen with $\mathrm{H} / \mathrm{H}$ cycling. An obvious corollary to hypoxia would be induction of VEGF or other angiogenic factors. Although VEGF has been shown to play a major role in the development of ROP $(3-8,5,6,20)$, our study demonstrates that the use of an IGF-1 analog had no major affects on VEGF levels in the serum, vitreous, or retina confirming the findings of Smith et al. (8).

The sVEGFR-1 is a splice variant of the membrane-type, VEGFR-1. It inhibits VEGF action in humans and mice by competitively binding to VEGFR (21). In our study, the use of JB1 during the first $3 \mathrm{~d}$ of life was associated with an increase in serum and retinal sVEGFR-1 at P14 and P21. The study by Aiello et al. (20) showed that intravitreous injection of soluble-VEGF-like chimeric proteins reduced retinal neovascular- 
ization by $50 \%$ in an animal model of ischemic retinopathy. The work by Rota et al. (22) showed an even greater decrease in retinal neovascularization in oxygen-exposed rats injected with sVEGFR-1. In our study, up-regulation of sVEGFR-1 with JB1x3 may explain the ocular benefits. However, reductions in ocular levels of sVEGFR-1 with JB1x7 may explain the evidence of vascular tortuosity in that group. Of the positive regulators of angiogenesis, VEGFA, CSF3, FGF, LEP, PDGFB, TGFA, RUNX1, and SHH were most affected by $\mathrm{H} / \mathrm{H}$ cycling and JB1 treatment. The effects on negative regulators of angiogenesis were variable, but the genes in the prolactin family were most affected by $\mathrm{H} / \mathrm{H}$ cycling and JB1 treatment. Of the TIMP family, TIMP-2 was mostly influenced by JB1x3 at P21. These findings add to the explanation of decreased OIR in the JB1x3 group and the evidence of vascular tortuosity with $\mathrm{JB} 1 \times 7$ treatment.

In summary, we have shown that systemic administration of JB1 influences ocular IGF-I levels. Short-term exposure has more beneficial ocular effects than long-term exposure. Early postnatal inhibition of IGF-I signaling with the use of JB1 has no major effects on ocular VEGF levels. The length of exposure to IGF-I blockers must be considered because long-term suppression of IGF-I may result in a later rebound upregulation in the ocular compartment and contribute to retinal neovascularization. The mechanisms involved in JB1 influence on sVEGFR-1 has not yet been determined. However, because sVEGFR-1 has been shown to act as a VEGF trap and reduce VEGF bioavailability, further confirmatory studies are needed to determine whether systemic JB1 should be used in ELBW infants for prevention or treatment of severe ROP.

\section{REFERENCES}

1. Smith LE 2003 Pathogenesis of retinopathy of prematurity. Semin Neonatol 8:469473

2. Saugstad OD 2007 Optimal oxygenation at birth and in the neonatal period. Neonatology 91:319-322

3. Coleman RJ, Beharry KD, Brock RS, Abad-Santos P, Abad-Santos M, Modanlou HD 2008 Effects of brief clustered versus dispersed hypoxic episodes on systemic and ocular growth factors in a rat model of oxygen-induced retinopathy. Pediatr Res $64: 50-55$
4. Pierce EA, Foley ED, Smith LE 1996 Regulation of vascular endothelial growth factor by oxygen in a model of retinopathy of prematurity. Arch Ophthalmol 114:1219-1228

5. McColm JR, Geisen P, Hartnett ME 2004 VEGF isoforms and their expression after a single episode of hypoxia or repeated fluctuations between hyperoxia and hypoxia: relevance to clinical ROP. Mol Vis 10:512-520

6. Werdich XQ, McCollum GW, Rajaratnam VS, Penn JS 2004 Variable oxygen and retinal VEGF levels: correlation with incidence and severity of pathology in a rat model of oxygen-induced retinopathy. Exp Eye Res 79:623-630

7. Hellström A, Engström E, Hård AL, Albertsson-Wikland K, Carlsson B, Niklasson A, Löfqvist C, Svensson E, Holm S, Ewald U, Holmström G, Smith LE 2003 Postnatal serum insulin-like growth factor I deficiency is associated with retinopathy of prematurity and other complications of premature birth. Pediatrics 112:10161020

8. Smith LE, Shen W, Perruzzi C, Soker S, Kinose F, Xu X, Robinson G, Driver S, Bischoff J, Zhang B, Schaeffer JM, Senger DR 1999 Regulation of vascular endothelial growth factor-dependent retinal neovascularization by insulin-like growth factor-1 receptor. Nat Med 5:1390-1395

9. Holmes JM, Duffner LA 1996 The effect of postnatal growth retardation on abnormal neovascularization in the oxygen-exposed neonatal rat. Curr Eye Res 15:403-409

10. Penn JS, Tolman BL, Henry MM 1994 Oxygen-induced retinopathy in the rat: Relationship of retinal nonperfusion to subsequent neovascularization. Invest Ophthalmol Vis Sci 35:3429-3435

11. Penn JS, Henry MM, Tolman BL 1994 Exposure to alternating hypoxia and hyperoxia causes severe proliferative retinopathy in the newborn rat. Pediatr Res 36:724-731

12. Higgins RD, Yu K, Sanders RJ, Nandgaonkar BN, Rotschild T, Rifkin DB 1999 Diltiazem reduces retinal neovascularization in a mouse model of oxygen induced retinopathy. Curr Eye Res 18:20-27

13. Ohkawa N, Shoji H, Kitamura T, Suganuma H, Yoshikawa N, Suzuki M, Lee T, Hisata K, Shimizu T 2010 IGF-I, leptin and active ghrelin levels in very low birth weight infants during the first 8 weeks of life. Acta Paediatr 99:37-41

14. Pietrzkowski Z, Wernicke D, Porcu P, Jameson BA, Baserga R 1992 Inhibition of cellular proliferation by peptide analogues of insulin-like growth factor 1 . Cancer Res 52:6447-6451

15. Pietrzkowski Z, Mulholland G, Gomella L, Jameson BA, Wernicke D, Baserga R 1993 Inhibition of growth of prostatic cancer cell lines by peptide analogues of insulin-like growth factor 1 . Cancer Res 53:1102-1106

16. Modanlou HD, Gharraee Z, Hasan J, Waltzman J, Nageotte S, Beharry KD 2006 Ontogeny of VEGF, IGF-I, and GH in neonatal rat serum, vitreous fluid, and retina from birth to weaning. Invest Ophthalmol Vis Sci 47:738-744

17. Wang X, Deng J, Boyle DW, Zhong J, Lee WH 2004 Potential role of IGF-1 in hypoxia tolerance using a rat hypoxic-ischemic model: activation of hypoxiainducible factor $1 \alpha$. Pediatr Res 55:385-394

18. LeRoith D, Werner H, Beitner-Johnson D, Roberts CT Jr 1995 Molecular and cellular aspects of the insulin-like growth factor I receptor. Endocr Rev 16:143-163

19. Hellstrom A, Perruzzi C, Ju M, Engstrom E, Hard AL, Liu JL, Albertsson-Wikland K, Carlsson B, Niklasson A, Sjodell L, LeRoith D, Senger DR, Smith LE 2001 Low IGF-1 suppresses VEGF-survival signaling in retinal endothelial cells: direct correlation with clinical retinopathy of prematurity. Proc Natl Acad Sci U S A 98:5804-5808

20. Aiello LP, Pierce EA, Foley ED, Takagi H, Chen H, Riddle L, Ferrara N, King GL, Smith LE 1995 Suppression of retinal neovascularization in vivo by inhibition of vascular endothelial growth factor (VEGF) using soluble VEGF-receptor chimeric proteins. Proc Natl Acad Sci U S A 92:10457-10461

21. Roy H, Bhardwaj S, Yla-Herttuala S 2006 Biology of vascular endothelial growth factors. FEBS Lett 580:2879-2887

22. Rota R, Riccini T, Zaccarini M, Lamartina S, Del Gallo A, Fusco A, Kovesdi I, Balestrazzi E, Abeni D, Ali RR, Capogrossi MC 2004 Marked inhibition of retinal neovascularization in rats following soluble-flt-1 gene transfer. J Gene Med 6:992-1002 